\title{
A Longitudinal Study of Human Exposure to Potential Nuclear Power Plant Risk
}

\author{
Dean Kyne ${ }^{1} \cdot$ Jason T. Harris ${ }^{2}$
}

Published online: 24 December 2015

(C) The Author(s) 2015. This article is published with open access at Springerlink.com

\begin{abstract}
This study constructs a potential risk index (PRI) for the 65 U.S.-based commercial nuclear power plant (NPP) sites in relation to their surrounding populations. Four risk levels are defined: low risk, moderate risk, high risk, and very high risk. Discrepancies that exist in the sociodemographic characteristics of the host communities' populations are examined as sorted by risk-level category. It is found that a greater percentage of minority groups are exposed to the highest levels of risk. In addition, percent "Hispanic" and percent "Other," a grouping that includes multiracial, mixed, interracial, as well as Hispanic and Latino groups (for example, Mexican, Puerto Rican, Cuban, or Spanish) are categories that show the greatest percent change in both the period 1990-2000 and 2000-2010.
\end{abstract}

Keywords Environmental justice $\cdot$ Nuclear power induced disaster $\cdot$ Nuclear power plant $\cdot$ Potential risk index

\section{Introduction}

The communities that host nuclear power plants (NPPs) inescapably face the various kinds of risks associated with them. In many instances, the NPP siting process was completed before concern for environmental justice

Dean Kyne

dean.kyne@utrgv.edu

1 Department of Sociology and Anthropology, The University of Texas Rio Grande Valley, Edinburg, TX 78539, USA

2 School of Health Sciences, Purdue University, West Lafayette, IN 47907, USA became widespread, and the host communities did not have an opportunity to participate in the environmental decisionmaking process. Lack of opportunity to participate in decision making resulted in the NPP being built in areas in which the communities involuntarily shoulder the potential risks of negative environmental impacts that could stem from the plant at any time. As a result, communities are saddled with a number of environmental justice issues without having possible solutions.

This study provides answers to these research questions: what are the levels of potential risk associated with NPPs and what are the sociodemographic characteristics of specific populations living within a 50-mile radius of a NPP? Specifically, the authors investigate the levels of potential risk associated with NPPs and the sociodemographic characteristics of specific populations. To answer these questions, the authors first identify the potential generic risks associated with individual NPPs. The authors then present the sociodemographic characteristics of the populations living in NPP host communities within a 50-mile radius of a NPP, sorted into four levels of potential risk-low, moderate, high, and very high. After discussing trends that are evident in the demographics of these populations, the authors discuss the environmental justice issues these populations face and summarize their findings.

\section{Potential Risks}

The emergence of commercial nuclear power can be traced back to 8 December 1953, the day President Dwight Eisenhower gave his "Atoms for Peace" speech, in which he highlighted his plan to transform nuclear fission materials - then, as now, the subject of much public fear-into a resource with a peaceful end use (Eisenhower 1953). On 18 
December 1957, Shippingport Atomic Power Station-the world's first commercial nuclear power plant, built on the Ohio River 25 miles northeast of Pittsburgh-began generating nuclear power (U.S. NRC 2011). As of 12 August 2012, there were 104 nuclear reactors located at 65 sites scattered across 31 states (U.S. NRC 2012a). The study included the 104 nuclear reactors in the data analysis. Four of these nuclear power plants were permanently shut down after 2012: they are Crystal River, Florida in February 2013; Kewaunee Carlton, Wisconsin in May 2013; San Onofre, California in June 2013; and Vermont Yankee, Vermont in December 2014 (U.S. NRC 2015).

In the 56 years since the reactors at Shippingport came online, NPPs have on occasion demonstrated a destructive potential that goes beyond what human capacity can manage. The first publically acknowledged NPP-related accident took place at Three Mile Island (TMI), 26 years after the Shippingport NPP came on line, when the plant encountered a major core-damage accident. Fortunately, the event came to an end on 28 March 1979 without requiring an evacuation. Residents living within a 5-mile radius of the plant, including preschool-aged children and pregnant women, were evacuated but only after 2 days had passed since the accident occurred (Three Mile Island Alert 2013).

The second demonstration of NPPs' powerful destructive potential occurred at Chernobyl NPP in Ukraine, seven years after the event at TMI. The Chernobyl plant experienced an accident that breached its reactor containment vessel and released radioactive effluents into the environment on 26 April 1986 (U.S. NRC 2013a). Areas within an 18-mile radius of the plant were abandoned and approximately 115,000 people were evacuated; an additional 220,000 people were evacuated in subsequent years. It was noted that the impacts were far felt beyond the 18-mile radius, reaching out to many areas of central and northern Europe (UNSCEAR 2012).

Twenty-five years after the Chernobyl accident, the third and most recent NPP-related accident occurred when an underwater earthquake triggered a tsunami that hit the Japanese coastline, causing massive damage at the Fukushima Daiichi NPP (U.S. NRC 2013d). The Japanese government in its initial response evacuated approximately 160,000 people living within a 12 - to 19 -mile radius of the Fukushima plant (Morris-Suzuki et al. 2012), but the impacted areas have proven to be much wider than the evacuated areas.

These accidents at NPPs are normally preceded by an event or a series of events that trigger or contribute to the damage done to the reactor core. When brought under control, events with the potential to have escalated into major accidents-that is, those of the type capable of causing reactor-core damage-are described as near-miss events. The U.S. Nuclear Regulatory Commission (NRC) issues an annual report detailing all near-miss events and classifies them according to three categories defined by the type of team sent out to inspect the event, which is in turn determined by the level or degree of severity of the event. There are three such teams-namely, the augmented inspection team (AIT), the incident inspection team (IIT) and the special inspection team (SIT). The AIT evaluates events that pose a 10-fold increase in risk, whereas the SIT investigates events that pose a 1000 -fold increase in risk level (Lochbaum 2011, 2012, 2013, 2014, 2015). In 2010, there were a total of 14 near-miss events (13 SIT and 1 AIT); in 2011, 15 (14 SIT and 1 AIT); in 2012, 14 (11 SIT and 3 AIT); in 2013, 10 (9 SIT and 1 AIT); and in 2014, 9 (9 SIT and 0 AIT). These figures hint at the regularity with which such plants pose a risk to their surrounding areas (Fig. 1). The total number of near-miss events coupled with a decline in total number of reactors showed a decline trend in the past two years.

Another risk associated with NPPs is that of contamination of the sort caused by the unmonitored and unplanned release of liquids. Commercial NPPs release radioactive materials into the environment, in either or both liquid or gaseous form, on a routine basis. There have been incidents of unplanned and unmonitored leaks of liquids that occurred at the Braidwood, Indian Point, Byron, and Dresden NPPs. The Liquid Radioactive Release Lessons Learned Task Force (LLTF) has been tasked with identifying the causes of such leaks (Richards et al. 2011). Their findings included the following: (1) the construction of plant components did not meet existing safety standards; (2) the components that caused or contributed to said leaks were not required to be monitored, nor were they subject to routine maintenance activities according to NRC regulations; (3) some components associated with subterranean leaks or with spent-fuel pools were not readily accessible

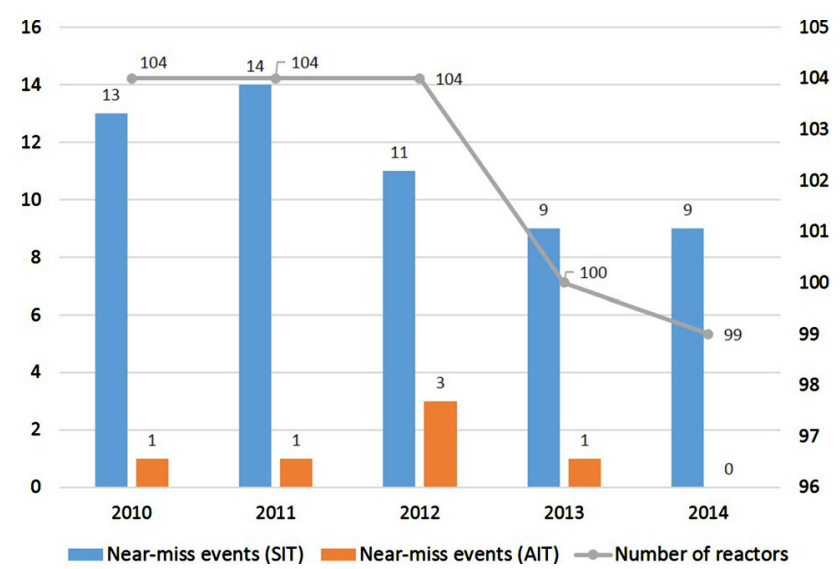

Fig. 1 Near-miss events taking place at U.S. commercial nuclear power reactors. Source Lochbaum (2011, 2012, 2013, 2014, 2015) 
or physically visible; (4) liquid leaks can enter undetected into groundwater; (5) the contamination of groundwater may go undetected because it is not required to be monitored according to existing NRC regulations; and (6) the contaminated groundwater could flow offsite undetected. The communities that host NPPs therefore, are at perpetual risk due to the presence of their local NPP.

A different potential risk associated with NPPs is their spent fuel-the highly radioactive used fuel rods that are removed from a nuclear reactor. Nuclear fuel rods are made of fissionable materials and retain their inherent destructive potential long after their initial use. Approximately $74 \%$ of all spent fuel is stored at the reactor site, most often in spent-fuel pools, while the rest are stored in dry-storage casks distributed across 33 states (U.S. GAO 2012). The U.S. Government Accountability Office (GAO) projects an annual 2000-metric-ton increase in the amount of spent fuel stored on site, with the current 70,000-metricton spent-fuel stockpile growing to 140,000 metric tons within a decade. New storage facilities are expected to be ready to begin accepting spent fuel in 15-40 years. The potential risks associated with such facilities include: (1) the release of radiation, which could have severe negative impacts on human health; and (2) a self-sustaining fire if and when the water is drained and the fuel rods are exposed to the air. Above all, the threats that are inherent to the 70,000-metric-ton spent-fuel stockpile cannot and must not be underestimated.

This spent fuel is also always vulnerable to terrorist attack (Holt and Andrews 2007). The terrorist attack on the World Trade Center in New York and the Pentagon building in Washington, DC on 11 September 2011-the so-called 9/11 attack-serves as reminder of the dire consequences and very real threat of a potential attack on a NPP. Afterwards, evidence came to light that revealed Al Qaeda had considered targeting a NPP in their initial plan of attack (Holt and Andrews 2007).

According to the National Academy of Sciences (U.S. NAS 2006), a successful attack on a spent-fuel storage facility would be difficult but is possible. In the event of such an attack, the spent fuel can become the source of a self-sustaining zirconium cladding fire, and will in such an event release a massive amount of radioactive materials. Communities that host NPPs therefore live with the unpredictable risk of exposure to a massive release of radiation.

The intent is that these materials will not permanently reside in the spent-fuel pools or stay safely in the drystorage casks housed at the reactor sites. When they are transported, they pose risk not only to the host communities but also to the communities at large along the transit route. The purpose of transporting spent fuels is to relocate them to storage space shared by multiple reactor sites operated by the same owner (U.S. NRC 2013b). According to Garrick (2003), between 1964 and 1997, a total of 3025 shipments moved 829 metric tons of heavy metal (MTHM) by road and an additional 1445 MTHM by rail. The transportation of such materials is closely supervised by the NRC and the U.S. Department of Transportation (U.S. NRC 2013b). Although regulated and supervised, the transportation - whether by road or by rail-has not been accident free. Between 1971 and 1995, there were four accidents on the highways and four on the rail lines; one highway accident resulted in the death of a driver and detectable emissions of radiation (Garrick 2003; U.S. NRC 2013e). All of the approximately 70,000 metric tons of spent fuel stored at reactor sites are waiting for shipment to high-level repositories, when such facilities are open and available to accept nuclear waste materials (U.S. NRC 2013b). With the Obama administration's 2009 decision to withdraw funding for the Yucca Mountain High-Level Nuclear Waste project, there is at present no permanent storage facility under development (Wald 2009).

Another risk that NPPs pose is inherent to their design and serves to highlight why it is critical that the design of a reactor that contains fissionable fuel rods during its normal operation be centered on safety. The Mark 1 containment vessel, first produced by GE in the 1960s and still in use at Fukushima NPP at the time of the accident there, contributed to the catastrophic events of 2011 (Zeller 2011). As early as 1975 , it was known that there had not been sufficient testing of the containment design and that any flaws that might persist could compromise the safety of the plant and its surroundings. But the warning did not lead to a halt in the operating of the design because it had by that time been widely accepted throughout the nuclear power industry. Harold Denton, a retired NRC official, pointed out that the probability of a Mark 1-type reactor bursting if the fuel rods were to enter into meltdown was approximately $90 \%$ (Denton 1987). In the United States, there remain 23 Mark 1 reactors that are exactly the same reactor design as those four reactors damaged at the Fukushima NPP site still in operation, located at 16 NPPs, including: Oyster Creek, New Jersey; Dresden, Illinois; and Monticello, Minnesota. The host communities of NPPs that still operate Mark 1 reactors are at greater risk of exposure to a Fukushima-like disaster than sites with safer reactor designs. Nuclear power plants are also vulnerable to seismic events of the type that played a role in triggering the catastrophe at Fukushima. The NPPs sited along the U.S. eastern seaboard in particular do not include in their designs any kind of measures meant to shield against the aftereffects of a strong earthquake (Koch 2011).

At the core of many of these concerns regarding NPPs is the fact that radiation poses a risk to public health. Radiation is a public health concern for two main reasons. First, 
humans' ability to structure their environment, as individuals, is rapidly decreasing because of population implosion. This results in the inability to completely avoid exposure from human-made sources of radiation. Second, radiation health effects are not unique and are detected only statistically. Standards and regulations for protection must be developed using the information provided by the scientific and medical communities with input from the public and government. Additionally, there are two other aspects of radiation exposure that need to be understood to properly evaluate the risk to public health. First, not all people exposed to radiation are affected equally. For example, children are much more vulnerable than adults to the effects of radiation. Second, radiation from internal emitters is in a sense different from external beam radiation. Irradiation by external beam radiation exists only as long as the source is present. Irradiation stops if the source is removed from the vicinity of the individual or the individual is removed from the vicinity of the source. However, radioactive materials taken into the body (that is via inhalation or ingestion) will continue to irradiate the individual for as long as it is in the body and the material remains radioactive.

Both the International Commission on Radiological Protection (ICRP 2007) and the U.S. National Academy of Sciences (U.S. NAS/NRC 2006) concluded that any exposure, including exposure to naturally occurring background radiation, creates an increased risk of cancer. This conclusion follows the linear non-threshold (LNT) model. Specifically, the LNT model assumes that, in the low dose range, radiation doses greater than zero will increase the risk of excess cancer and/or heritable disease in a simple proportionate manner. While further research is needed to undoubtedly prove this is true, current findings support this model and it has been adopted in standards and regulations worldwide. Regardless of whether or not the source of radiation is human-made, as in the case of NPPs, or natural, as exposure increases so does risk.

The communities that host such facilities shoulder the potential risks associated with nuclear power from the time the plant begins operation until the time it is decommissioned-for a typical reactor design, the use life is between 40 and 60 years (U.S. NRC 2014). After a plant is shutdown, it takes under normal conditions 50 years for the reactor to cool; this is followed by a period of decommissioning that normally takes another 60 years. For example, Crystal River Unit 3 was permanently shut down on 2 February 2013 and NRC scheduled to complete decommission in 2073 (U.S. NRC 2014). The NRC has advanced three strategies for dealing with end of use at a NPP: (1) DECON, or decommissioning strategies; (2) SAFSTOR, or deferred dismantling; and (3) ENTOMB, or the permanent encasing on site of radioactive contaminants
(U.S. NRC 2013c). For example, Hallam Nuclear Power Plant, Nebraska, a NPP with a short use life, was decommissioned in 1971. All potential containments were at that time buried underground. Since then, the Department of Energy, working in conjunction with the Nebraska Department of Health, has monitored the entombment site for possible groundwater contamination and radiation, and will continue to do so for a period of 119 years, until 2090 (Nebraska Energy Quarterly 1997). Figure 2 shows the location of the permanently decommissioned U.S.-based commercial nuclear power reactors as of August 2012.

Above all, the potential risks associated with NPPs can be explained by Perrow's normal accidents theory. As noted previously, NPPs are complex and tightly coupled systems and complexity produces unknown risks. According to Perrow's theory:

Nothing is perfect, neither designs, equipment, procedures, operators, supplies, or the environment. Because we know this, we load our complex systems with safety devices in the form of buffers, redundancies, circuit breakers, alarms, bells, and whistles. Small failures go on continuously in the system since nothing is perfect, but the safety devices and the cunning of designers, and the wit and experience of the operating personnel, cope with them. Occasionally, however, two or more failures, none of them devastating in themselves in isolation, come together in unexpected ways and defeat the safety devicesthe definition of a "normal accident" or system accident. If the system is also tightly coupled, these failures can cascade faster than any safety device or operator can cope with them... if the accident brings down a significant part of the system, and the system has catastrophic potential, we will have a catastrophe. (Perrow 1999, pp. 356-357)

According to Perrow's analysis, the risks associated with NPPs therefore should be seen as intrinsic to the system, normal, and as something that cannot be avoided.

\section{Method}

This section discusses the study area, variables, data, method, and construction of the NPP PRI index.

\subsection{Study Area}

This study focuses on two distance areas surrounding the 65 NPPs. The two distance areas are similar to those identified in the recent study of Kyne (2015). One is those areas within a 50-mile radius of any one of the 65 U.S.based NPPs; the other is those areas outside of a 50-mile 


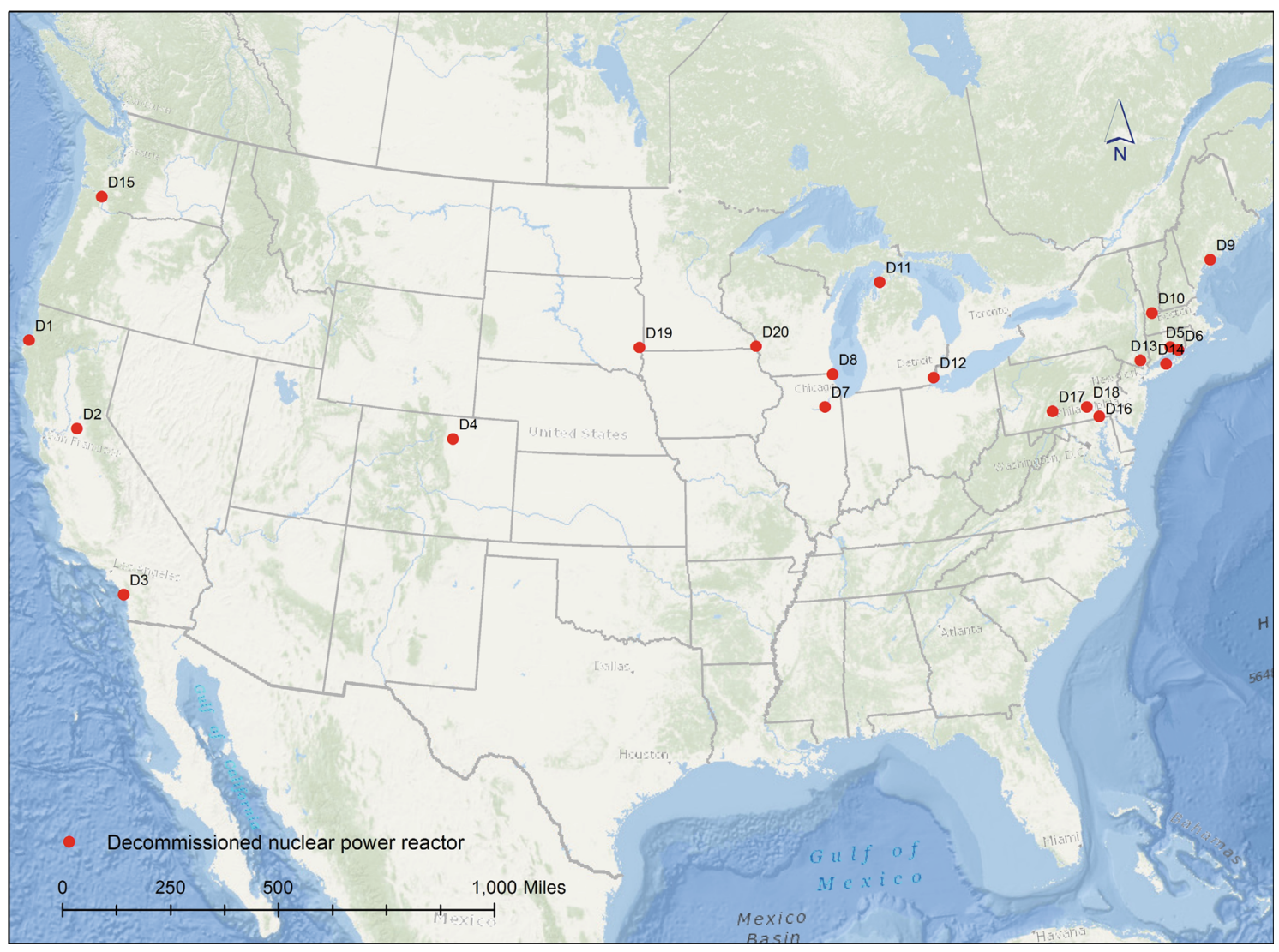

\begin{aligned} & \hline Index Plant Name, Reactor \\ & \hline D1 Humboldt Bay Nuclear Power Plant, Humboldt Bay 3 \\ & D2 Rancho Seco Nuclear Generating Station, Rancho Seco \\ & D3 San Onofre Nuclear Generating Station, Unit 1 \\ & D4 Fort Saint Vrain Generating Station, Fort St. Vrain \\ & D5 Connecticut Yankee, Haddam Neck \\ & D6 Millstone Power Station, Unit 1 \\ & D7 Dresden Nuclear Power Station, Unit 1 \\ & D8 Zion Nuclear Power Station, Zion 1 \& 2 \\ & D9 Maine Yankee Nuclear Power Plant, Maine Yankee \\ & D10 Yankee-Rowe Nuclear Power Station, Yankee-Rowe \\ & D11 Big Rock Point Nuclear Plant (Monticello) \\ & D12 Fermi, Unit 1 \\ & D13 Indian Point Nuclear Generating Station, Unit 1 \\ & D14 Shoreham Nuclear Power Station, Shoreham \\ & D15 Trojan Nuclear Power Plant, Trojan \\ & D16 Peach Bottom Atomic Power Station, Unit 1 \\ & D17 Saxton \\ & D18 Three Mile Island Nuclear Station, Unit 2 \\ & D19 Pathfinder Atomic Plant, Pathfinder \\ & D20 La Crosse Nuclear Generating Station, La Crosse \\ &$*\end{aligned}$

Fig. 2 Permanently decommissioned U.S.-based commercial nuclear power reactors as of August 2012. Data source U.S. NRC (2012b). Note *Located in currently operating nuclear power plant site. \#Entire plant site with the two reactors was permanently shut down

radius and yet that are located in the state(s) that fall within said 50-mile radius. There are 20 permanently deactivated reactors located at NPPs that otherwise remain active. Kyne (2015) provided a notion that these 20 reactors do not pose the same level of risk as do reactors currently in operation, which pose increased risks as a result of their day-to-day operation, the possibility of core meltdown-type accident, and from their release of gaseous and liquid radioactive effluents. However, they could be regarded as a potential source of radiation risk from any spent fuel stored on site. The reason for exclusion was to ensure apples to apples comparison. 


\subsection{Study Variables}

The study includes variables that are similar to those used in the study of Kyne (2015). The racial/ethnic variables included the categories (1) White-Percent White as percent of all non-Hispanic Whites; (2) Black-Percent Black as percent of non-Hispanic Blacks or African Americans; (3) Asian-Percent Asian as percent of Asian, and Native Hawaiian or Other Pacific Islander; (4) Hispanic-Percent Hispanic as percent of people who are Hispanic origin; (5) Native American-Percent Native American as percent of American Indian or Alaska Native; (6) Other-Percent Other as percent of Some Other Race who are not included in the White, Black, or African American, American Indian or Alaska Native, Asian, and Native Hawaiian or Other Pacific Islander race categories, or whose identify themselves as multiracial, mixed, interracial, or a Hispanic or Latino group (for example, Mexican, Puerto Rican, Cuban, or Spanish); and (7) Color-Percent Color as percent of all other races except non-Hispanic Whites. Similarly, the study included the socioeconomic variables that were also used in the study of Kyne (2015), which are renter-occupied housing, unemployment rate, percent living in poverty, mean household income, and percent composition at the census-tract level.

Another study variable was distance, which was measured as Euclidean distance in miles from the census-tract center point to the NPP using the ENVI's ArcMap program (Kyne 2015). The distance was used to investigate whether and how disparities in certain demographic characteristics were associated with the distance from a NPP.

Other study variables relate to radioactive materials and radiation dosage levels. These include: radioactive effluents released from a reactor at a given NPP; the radiation dose able to be delivered by those effluents; and the amount of radiation absorbed by the human body upon exposure.

\subsection{Study Data}

This study included multiple datasets. To investigate demography-based disparities in the study areas, this study required three discrete datasets:

(1) First, for demographic characteristics, data were obtained from the United States Census Bureau and GeoLytics (GeoLytics 2012a, 2012b, 2012c), which were also used in the previous study (Kyne 2015). The census tract level data allowed for comparison in the study years because the census tract boundaries are normalized to those of the 2010 data.

(2) Similar to the datasets used in the study of Kyne (2015), this study includes the 2010 Census TIGER/ Line Shapefiles and the 2010 U.S. Census Summary
File 1 Demographic Profile (DP1) for the United States and Puerto Rico were used in order to join the normalized data containing study variables (United States Census Bureau 2010). The 2010 Census TIGER/Line Shapefiles were purposefully used because the most recent decadal dataset used in this study was 2010. In addition, the data in 1990 and 2000 were normalized to those of the 2010 boundaries.

(3) The location of each of the 104 nuclear reactors located at 65 sites that are currently in operation in the United States was obtained from the NRC's website (U.S. NRC 2012b). As noted earlier, there are four power plants that were permanently shut down before the time this manuscript is published. It results in a fleet of 99 reactors located in 61 sites across 30 states as of August 2015 (U.S. NRC 2015).

To study the extent and severity of exposure to radiation and radioactive effluents, our research required access to two datasets:

(1) Radioactive effluents data from 2001 to 2008 were acquired via the Center for Advanced Energy Studies (Harris 2013). The effluents data include both liquid and gaseous data for both pressurized water reactors (PWRs) and boiling water reactors (BWR).

(2) The reactor oversight dataset includes seven variables that detail three strategic areas-reactor safety, radiation safety, and safeguards. The seven variables are: initiating events, mitigating systems, barrier integrity, emergency preparedness, public radiation safety, occupational radiation safety, and physical protection. These have been published in 1Q/2012 ROP Performance Indicators Summary (U.S. NRC 2012a).

To examine the risks of natural disaster associated with individual NPPs, data regarding earthquakes (FEMA 2013; USGS 2013), hurricanes, tornadoes, and volcanoes (The Daily Beast 2011) were also obtained. These data contain earthquake information measured on a seven-point scale based on the United States Geological Survey (USGS) map; hurricane predictions based on historical data as compiled by the USGS; the number of predicted tornado days per century based on a dataset spanning 1921-1995 (as complete and predictive a measure of tornadoes as is currently available); and NPPs sorted by proximity to an active volcano.

\subsection{Study Method}

This study mainly utilized two research methods in searching answers to the research question. First, the study used center point-distance suggested in the study of Kyne 
Fig. 3 A conceptual framework used in constructing a PRI for U.S.-based NPPs

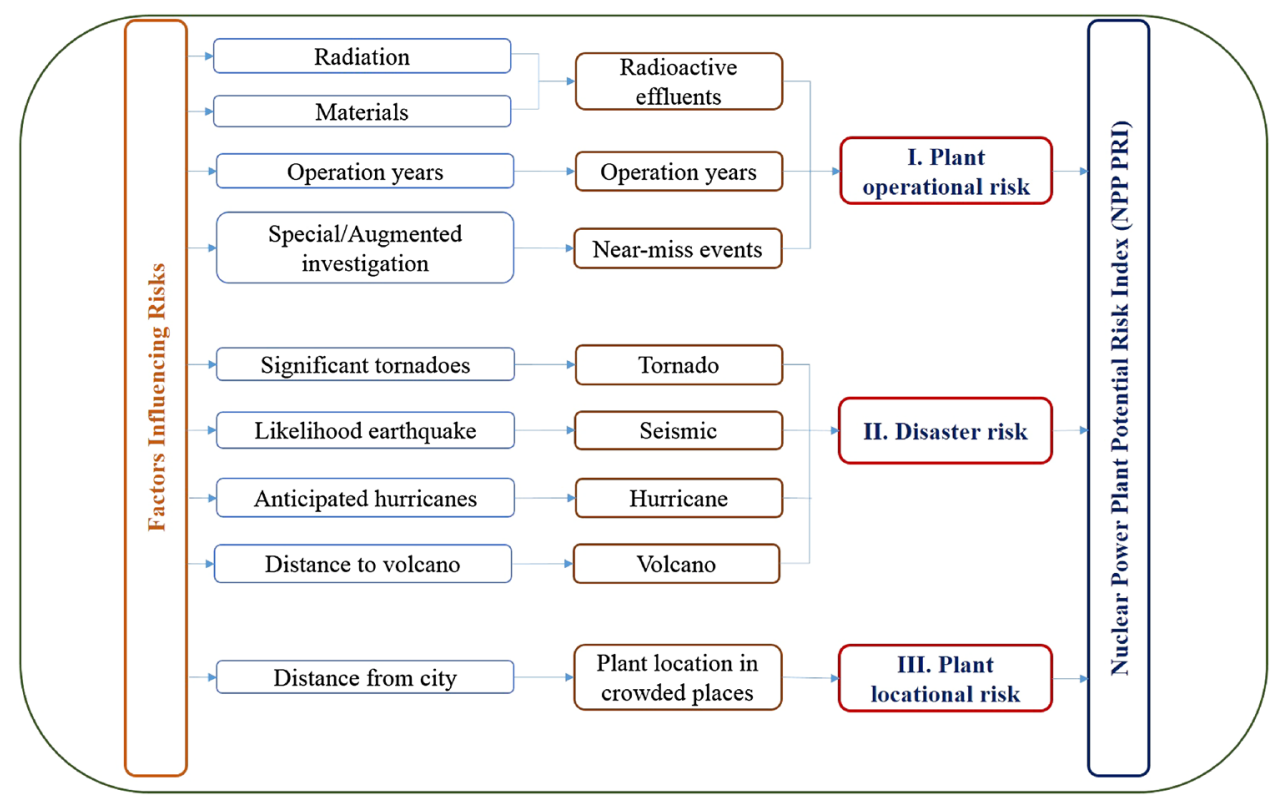

(2015) to measure distance from the NPPs to the hosting communities that were located within a 50-mile radius from the nearest NPP. Measuring the distance included two steps. Step one included determining the geographic center point of each included census tract in ArcMap 10.1 and next selecting those geographic center points that fell within a 50-mile radius of the nearest NPP, identified using the "near" tool in ArcMap 10.1. This method provided the exact distance between the census tracts' center points and the relevant NPPs. Step two included collapsing the demographic characteristics of population living in the census tracts within a 50-mile radius. Second, the study constructed a potential risk index (PRI), which is a composite index that can be applied to all U.S.-based NPPs. The composite index measures the potential risks associated with NPPs. According to the OECD (2008), "a composite indicator is formed when individual indicators are compiled into a single index on the basis of an underlying model of the multi-dimensional concept that is being measured" (OECD 2008, p. 13). To construct the index, a five-step process was followed: (1) construct a theoretical framework; (2) select data; (3) normalize the data; (4) determine the weights to be assigned to the different categories and types of data; and (5) aggregate the data.

\subsection{NPP Potential Risk Index (NPP PRI)}

A conceptual framework was initially constructed that includes the three cornerstone potential risks that confront any NPP_plant operational risks, natural disaster risks, and plant locational risk (Fig. 3). The potential risks at any NPP can stem from the plant itself-from its day-to- day operations, the normal aging of the plant, and/or the continued, ongoing exposure of the plant, its equipment and its surroundings to radioactive effluents and their byproducts. Next, any NPP could experience an accident, including a core-damage event, which could be triggered by a natural disaster such as an earthquake, hurricane, or tornado. The plant's physical location, especially when near to densely populated areas, influences the level of the potential risk it poses. If a given plant is sited in proximity to a densely populated area, then the plant would be potentially exposed to human-caused hazards such as an airplane crash or a terrorist attack. The potential risk level of each NPP can be measured across these three dimensions.

Radioactive effluents are measured by the radioactive materials that comprise the waste stream, and the associated radiation doses those materials deliver or carry with them. Data for two types of radioactive effluents-gaseous and liquid effluents-were summed to arrive at a total volume of radioactive effluents released by each NPP. The amount released was normalized according to the amount of electricity generated at each site. The effective dose data, which were computed using the normalized total radioactive effluents, were then estimated using a dose estimate model established by the United Nations Scientific Committee on the Effects of Atomic Radiation (UNSCEAR) and employed by Harris and Miller (2008). The dose estimate model made an assumption that a model NPP site has a population density of 1036/square mile and 52/square mile for within 31 miles of the site and within 772 miles of the site, respectively (Kyne 2015). This model site provides an estimate of the collective effective dose 
(CED) per unit release for different release categories. The CED per unit of electrical energy (man Sv $(\mathrm{GW} a)-\wedge 1$ ) then can be obtained by multiplying the normalized releases by the UNSCEAR-calculated values for CED per unit release. Both the radioactive effluents released and their effective dose data for the period 2001-2008 were included in these calculations, and were given equal weight in constructing the NPP PRI presented here.

Another type of data is near-miss events. The NRC typically reports on near-miss events at NPPs. These events are termed "near miss" because they raise the risk of damage to the reactor core and endanger the safety of workers and the public, but do not result in core meltdown or radioactive effluent release (Lochbaum 2011, 2012, 2013, 2014, 2015). Analysis of a near-miss event will, depending on the potential risk level of the event, involve one of the NRC's three investigative teams: the augmented inspection team; the incident inspection team; or the special inspection team. In the past 3 years, there have been reports of near-miss events issued by each of the first two teams. Known near-miss events that occurred in 2010, 2011, and 2012 were accounted for in constructing the NPP PRI when the data analyses were conducted in August 2013. According to the World Nuclear Association (2013), most NPPs are designed for a use life of 30-40 years. As this window is extended out beyond planned operational life, NPPs will face three problems. First, there are problems at aging plants with components and parts that need to be replaced, some of which are difficult to access. Second, there are issues with obsolescence, as many NPPs currently in operation still use analog instrument and control systems. Third, due to heat and neutron irradiation, a plant's materials degrade with age. In the United States, World Nuclear Association (2013) anticipated that more than 100 reactors will be granted license extensions from 40 to 60 years. These extensions pose a safety risk and raise questions about the reliability at older NPPs. The age of the plant, or its duration of operation in years, can be computed by subtracting the year of issue of its commercial operating license from the current year. The longer a NPP has been in operation, the more likely it is that it may pose an increasing risk.

A natural disaster such as an earthquake, hurricane, or tornado may trigger a nuclear accident that can result in damage being done to the reactor core. The likelihood of an earthquake striking a NPP was estimated with data taken from the United States Geologic Survey's (USGS) National Seismic Hazard Map. This map expresses the severity of horizontal shaking as a percentage of $\mathrm{g}$ - the acceleration of a falling object due to gravity-and displays shaking intensity with seven color-coded categories that denote "seismic design categories" (USGS 2014). The categories correspond to the likelihood of an earthquake occurring that would lead to shaking and displacement of various intensities (FEMA 2013). The USGS map was overlaid on a map showing the locations of all 65 NPPs in the United States. The output display was then used to assign each NPP a value for the likelihood that an earthquake will occur, on a seven-point scale ranging from 0 (least likely) to 6 (most likely). Other natural hazards were considered less likely to generate high risk levels, but were included in the index analysis for completeness and because of their importance for particular NPP sites. Hurricane risk was measured by taking into account the number of hurricanes predicted to make landfall near the site of a NPP in the century to come (The Daily Beast 2011). Tornado risk was measured by considering the average number of significant tornadoes documented between 1921 and 1995 (The Daily Beast 2011). Volcano risk was measured by distance miles from the nearest volcano (The Daily Beast 2011). Finally, locational risk was measured by distance in miles from the nearest city.

Selected study indicators were normalized in order to render them comparable to one another. The min-max method was used to create an identical range by transforming indicators to a scale that would allow for direct comparisons. The method called for subtracting the minimum value from the original value and then dividing by the range of the indicator values. In other words, each variable was rescaled to a range from 0 to 100 , using the following formula: $\quad c_{i}^{\prime}=\left[\left(c_{i}-c_{\min }\right) /\left(c_{\max }-c_{\min }\right)\right] \times 100$, where $c_{i}^{\prime}=$ normalized or rescaled value; $c_{i}=$ original value; $c_{\min }=$ minimum value in the variable; and $c_{\max }=$ maximum value in the variable (OECD 2008; Tate et al. 2010).

Construction of a composite index requires the application of appropriate weighting methods. Principal component analysis (PCA) and factor analysis (FA) methods were applied to aid in selecting appropriate weights, which were then used to compile the selected study indicators into a single composite index. Factor analysis with varimax rotation was then performed in order to minimize subindicators that had a loading on the same factor, which allowed us to study that subset of the principal components that accounted for the largest amount of variance. Four factors that were associated with eigenvalues larger than one were selected; these factors were responsible for a cumulative contribution to the overall variance of $63.19 \%$ (Table 1). Weights from the factor loading results then were computed. To do so, the weights first were normalized by the squared factor loading (OECD 2008; Tate et al. 2010). For example, radiation dose in factor 4, of 0.863 loading, was normalized to 0.608 , according to the formula $0.608=\left(0.863^{\wedge} 2\right) / 1.2238$. After normalizing the factor loadings, the composite weights were obtained. Following the method Nicoletti et al. (2000) prescribe, four subindicators were grouped with the highest factor loadings 
Table 1 Factor loadings of the NPP PRI using the varimax method

\begin{tabular}{|c|c|c|c|c|c|c|c|c|}
\hline \multirow[t]{2}{*}{ Variable } & \multicolumn{4}{|c|}{ Factor loadings } & \multicolumn{4}{|c|}{ Normalized factor loadings } \\
\hline & Factor 1 & Factor 2 & Factor 3 & Factor 4 & Factor 1 & Factor 2 & Factor 3 & Factor 4 \\
\hline Radiation dose & -0.010 & 0.096 & -0.068 & 0.863 & 0.000 & 0.006 & 0.003 & 0.608 \\
\hline Radioactive effluents & -0.121 & 0.764 & 0.087 & 0.306 & 0.009 & 0.398 & 0.006 & 0.077 \\
\hline Years in operations & -0.282 & -0.725 & 0.112 & 0.186 & 0.049 & 0.359 & 0.009 & 0.028 \\
\hline Near-miss events & 0.068 & 0.242 & 0.189 & -0.116 & 0.003 & 0.040 & 0.026 & 0.011 \\
\hline Significant tornados & -0.565 & 0.348 & 0.477 & -0.330 & 0.197 & 0.083 & 0.166 & 0.089 \\
\hline Likelihood of earthquake & 0.751 & 0.186 & 0.097 & 0.020 & 0.348 & 0.024 & 0.007 & 0.000 \\
\hline Anticipated hurricanes & -0.131 & -0.055 & -0.835 & 0.117 & 0.011 & 0.002 & 0.508 & 0.011 \\
\hline Plant location distance from city & -0.026 & -0.360 & 0.605 & 0.448 & 0.000 & 0.088 & 0.267 & 0.164 \\
\hline Distance from volcano & 0.789 & 0.015 & 0.112 & -0.121 & 0.383 & 0.000 & 0.009 & 0.012 \\
\hline Eigenvalues & 1.6222 & 1.4668 & 1.3742 & 1.2238 & & & & \\
\hline Explained variance/total & 0.2853 & 0.2579 & 0.2416 & 0.2152 & & & & \\
\hline
\end{tabular}

Italicized values indicate strong association between the variables and the latent factors, Factor 1, 2, 3, and 4

into four composite indicators: (1) subindicator 1 includes significant tornados (with a weight of 0.197 ), likelihood of earthquake (weight $=0.348$ ), and distance from volcano (weight $=0.383)$; (2) subindicator 2 contains radioactive effluents (weight $=0.398$ ), years in operation (weight $=$ 0.359 ), and near-miss events (weight $=0.040$ ); (3) subindicator 3 comprises anticipated hurricanes (weight $=0.508$ ) and plant location distance from city (weight $=0.267$ ); and (4) subindicator 4 is constituted by radiation dose (weight $=0.863$ ). Next each of the four immediate subindicators was aggregated by applying the weight of the proportion of the explained variance in the dataset: 0.2853 for subindicator $1(0.2853=1.6222 /(1.62+1.47+1.37+$ $1.22)$ ); 0.2579 for subindicator $2 ; 0.2416$ for subindicator 3 ; and 0.2152 for subindicator 4 . The NPP PRI was obtained via the following equation: NPP PRI $=(0.2853 \times$ subindicator $1+0.2579 \times$ subindicator $2+0.2416 \times$ subindicator $3+$ $0.2152 \times$ subindicator 4 ).

To understand the relative risk levels that exist among the 65 NPPs operating in the United States, the composite index scores were ranked from highest to lowest. These were grouped into four categories based on their percentile rank: (1) low risk, between 0 and 25 th percentile; (2) moderate risk, between $>25$ th and 50th percentile; (3) high risk, between $>50$ th and 75 th percentile; and (4) very high risk, between $>75$ th and 100th percentile. There are 16 plants in each of the categories low risk, moderate risk, and high risk, and 17 in the category very high risk (Table 2; Fig. 4).

\section{Findings and Discussion}

This section discusses sociodemographic compositions by NPP PRI level and changes in demographic compositions during the study years. First, the study provides a discussion on findings of demographic characteristics of the population living within a 50-mile radius and their respective exposure to different levels of NPP PRI in 2010. Second, the study traces changes of demographic characteristics between the two study periods, 1990-2000 and 2000-2010, and looks into changes in demographic characteristics associated with the four levels of NPP PRI in the two study periods.

\subsection{The Sociodemographic Composition of Populations According to NPP PRI Level}

The 17 NPPs classified as very high risk accounted for the largest geographic area, some 83,640 square miles, or $28 \%$ of the total land area occupied by NPPs in the United States. The highest percent Black (22\%) among potentially at-risk populations was found in the host communities of NPPs sorted into this subgroup. The second largest area, 74,961 square miles or $25 \%$ of the total area occupied by NPPs in the United States, was associated with the 16 NPPs assigned to the high-risk category of the PRI as of 2010 (Table 3; Fig. 5). Because the census tract boundaries for prior-year data were normalized to the 2010 censustract boundaries, these areas do not change when analyzing U.S. Census data for the years 1990 and 2000.

The at-risk populations included a greater percent Asian, percent Hispanic, percent Native American, percent Other, and percent Color than compared to their counterpart populations living in communities outside of the areas prone to nuclear power-related risks for each of the four PRI categories (Table 3). Populations living in close proximity to a NPP classified as low risk registered the highest percent unemployed and the highest percent living in renter-occupied housing units. Similar patterns were identified in the 1990 and 2000 U.S. Census data (Fig. 4). 


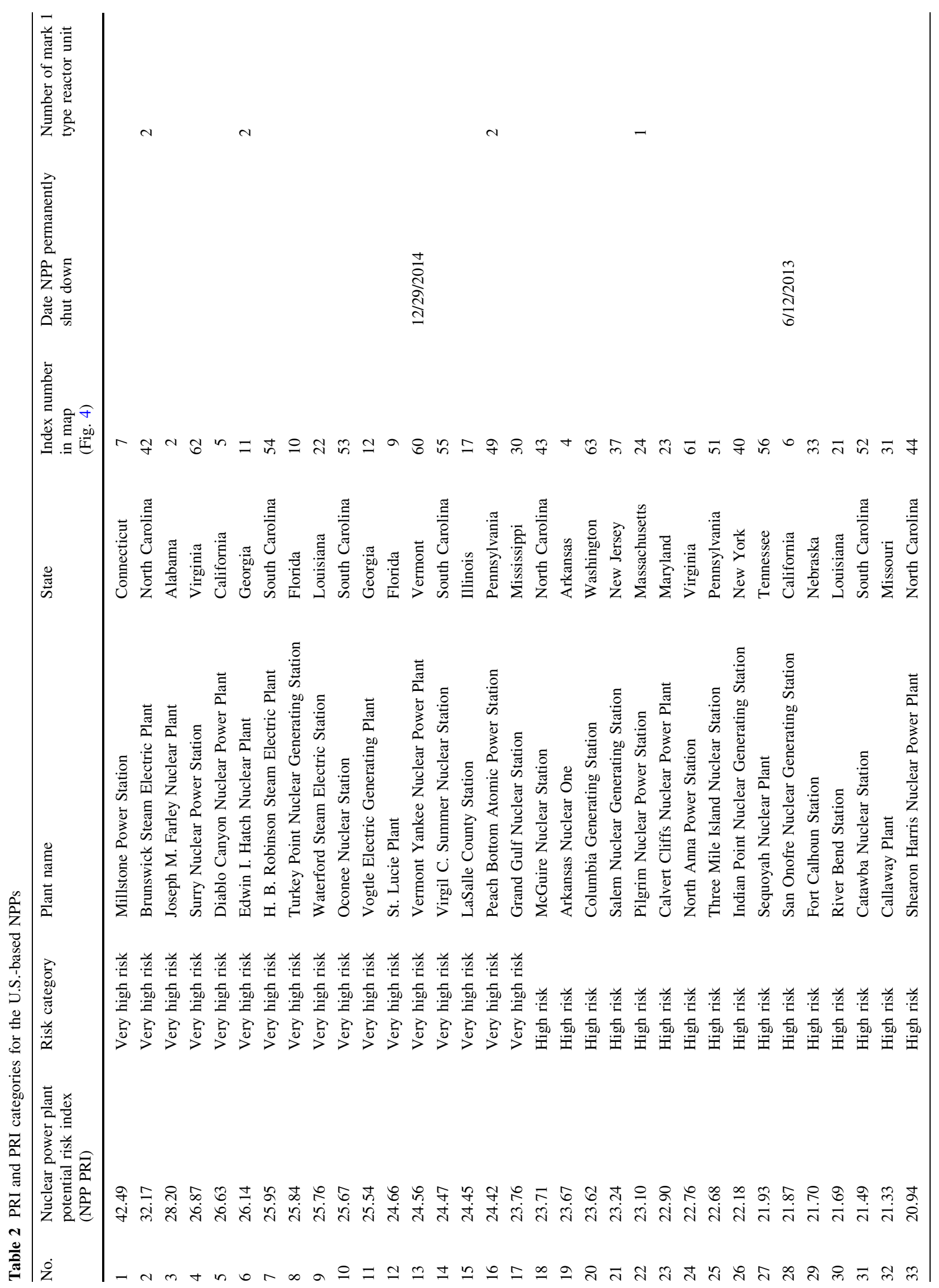




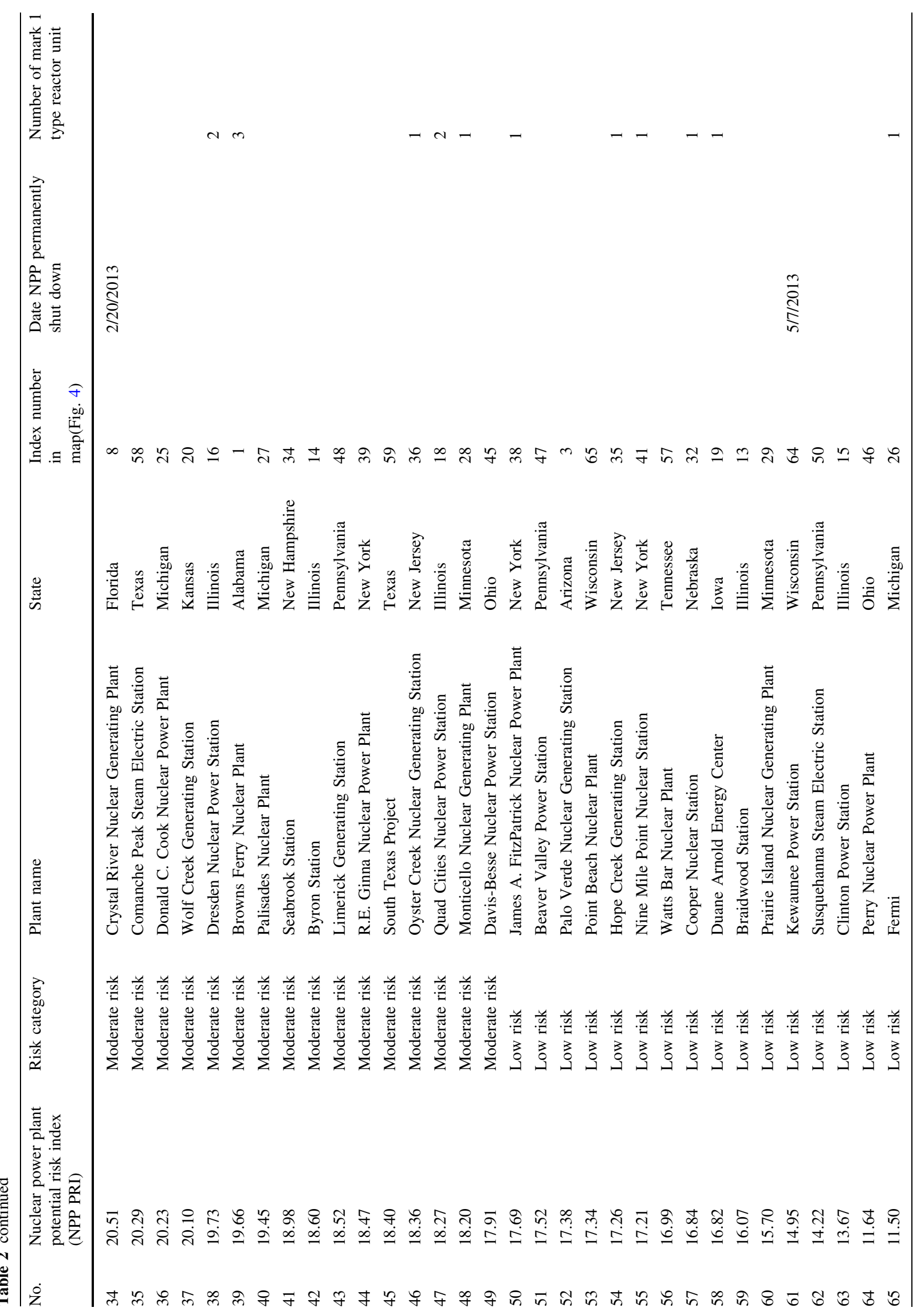




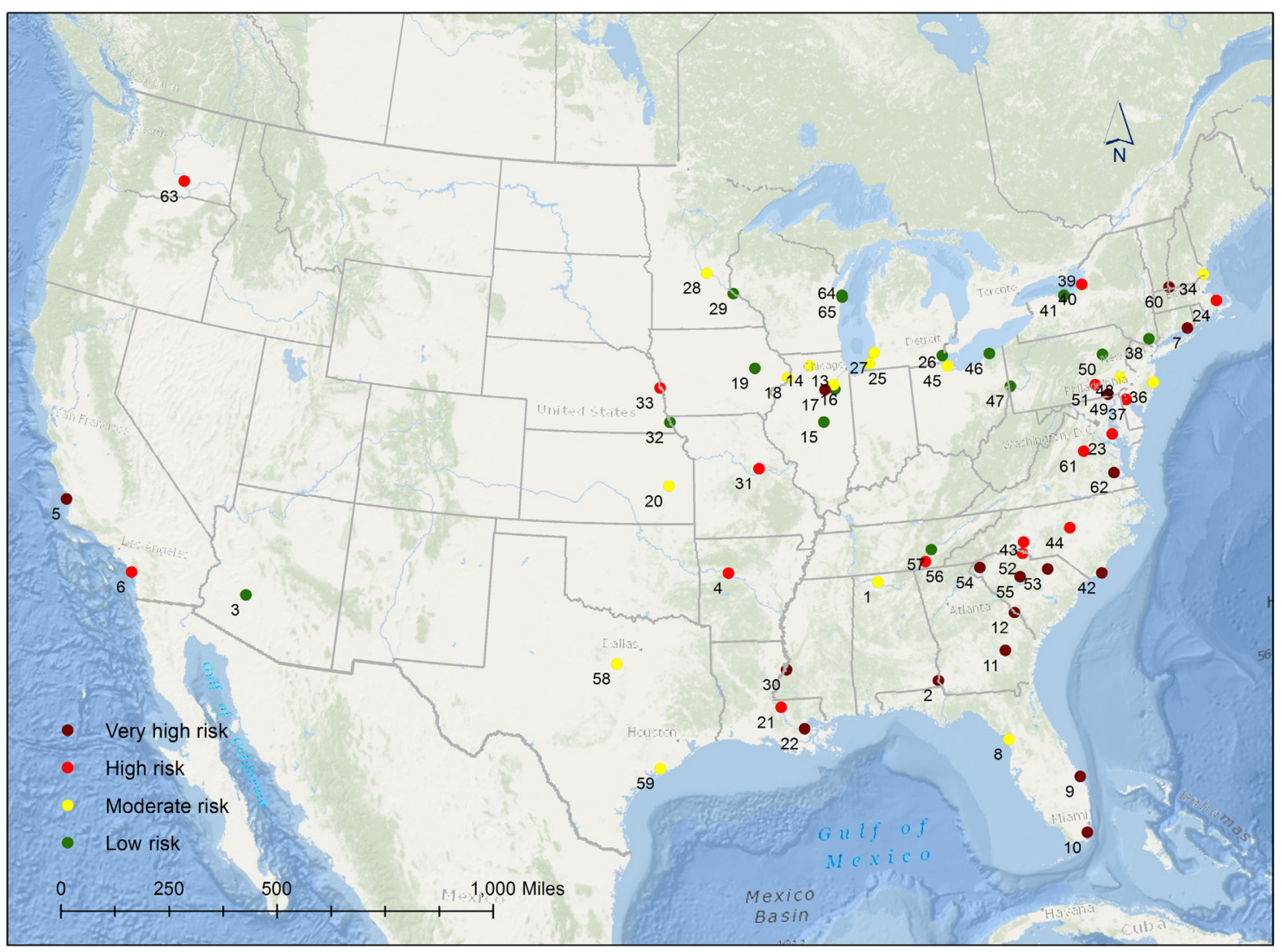

Fig. 4 Distribution of NPP-related potential risk in the United States

In addition to the highest percent Black (22.34\%) occurring among the host communities of NPPs classified as being at very high risk, these same NPPs were also associated with the highest percent Color (42.60\%) (Table 3). Similar patterns were observed in the data from 1990 to 2000 (Fig. 4).

In short, the minority groups who are in low socioeconomic status inevitably shoulder the burden of potential risks associated with the NPPs. The study provides two notions in regard to demographic characteristics of populations and their exposure to the four levels of risks. One notion is that there are variations in exposure to the four levels of risks among the populations living within a 50-mile radius. The other notion is that the minority groups living within a 50-mile radius inevitably expose to the four different levels of risks while their counterparts in the outlying areas do not expose to the risks. According to Bullard (1996, p. 493), "all people and communities are entitled to equal protection of environmental and public health laws and regulation." It is obvious that the communities living within a 50-mile radius from the nearest NPP faced environmental justice issues (Fig. 5). The findings reflect the fact that authorities made environmental decisions on siting of U.S. NPPs without incroporating consideration of unequal impacts from environmental hazards (Kyne 2015).

\subsection{Demographic Trends by PRI Category}

Changes over time in the demographics of the populations associated with each of the four PRI categories across two periods-1990-2000, and 2000-2010 were also examined. Between 2000 and 2010, percent Asian showed the greatest increase, up $48 \%$ in areas classified as moderate risk; in those same areas, meanwhile, percent people living below the federal poverty line increased $1.97 \%$ points. Percent Hispanic and percent Black registered the most pronounced increases, 44 and $17 \%$, respectively, in areas classified as high risk. Overall, percent Color showed the greatest increase in the high risk category, up 54 and $30 \%$, respectively, in 1990-2000 and 2000-2010.

The findings show that minority racial and ethnicity groups including Asian, Black, Color, Hispanic, and Native American increased during the two study periods, 1990-2000 and 2000-2010 (Table 4; Fig. 6). 
Table 3 Demographic characteristics of populations living within a 50-mile radius of a NPP, classified according to four PRI categories using the 2010 U.S. Census data

\begin{tabular}{|c|c|c|c|c|c|c|}
\hline 2010 & Low risk & Moderate risk & High risk & Very high risk & Total & Outside \\
\hline Tracts & 8445 & 5659 & 4966 & 4325 & 23,395 & 49,662 \\
\hline Tract area (sq. mile) & 71,490 & 70,709 & 74,961 & 83,640 & 300,801 & $3,495,942$ \\
\hline Total population & $31,989,280$ & $24,130,408$ & $22,277,072$ & $17,674,888$ & $96,071,648$ & $207,893,616$ \\
\hline White & $21,626,292$ & $18,518,612$ & $15,479,203$ & $12,423,962$ & $68,048,072$ & $156,847,632$ \\
\hline Black & $5,402,879$ & $2,861,589$ & $3,268,325$ & $3,949,417$ & $15,482,210$ & $22,496,542$ \\
\hline Asian & $2,036,120$ & $1,041,474$ & $1,398,483$ & 399,936 & $4,876,013$ & $9,801,153$ \\
\hline Native American & 109,554 & 67,366 & 95,330 & 60,454 & 332,704 & $2,147,761$ \\
\hline Other & $2,814,435$ & $1,641,369$ & $2,035,730$ & 841,119 & $7,332,653$ & $16,600,536$ \\
\hline Hispanic & $4,772,429$ & $2,803,678$ & $3,462,599$ & $2,949,929$ & $13,988,635$ & $33,738,896$ \\
\hline Color & $12,612,146$ & $7,067,641$ & $8,591,788$ & $7,529,264$ & $35,800,840$ & $71,591,664$ \\
\hline White $(\%)$ & 67.60 & 76.74 & 69.48 & 70.29 & 70.83 & 75.45 \\
\hline Black (\%) & 16.89 & 11.86 & 14.67 & 22.34 & 16.12 & 10.82 \\
\hline Asian $(\%)$ & 6.37 & 4.32 & 6.28 & 2.26 & 5.08 & 4.71 \\
\hline Native American (\%) & 0.34 & 0.28 & 0.43 & 0.34 & 0.35 & 1.03 \\
\hline Other $(\%)$ & 8.80 & 6.80 & 9.14 & 4.76 & 7.63 & 7.99 \\
\hline Hispanic (\%) & 14.92 & 11.62 & 15.54 & 16.69 & 14.56 & 16.23 \\
\hline Color $(\%)$ & 39.43 & 29.29 & 38.57 & 42.60 & 37.26 & 34.44 \\
\hline Renter-occupied housing units (\%) & 36.28 & 26.38 & 29.32 & 28.18 & 30.69 & 28.73 \\
\hline College degree or higher $(\%)$ & 31.44 & 30.66 & 30.49 & 26.07 & 30.03 & 26.9 \\
\hline Unemployed (\%) & 8.37 & 7.97 & 7.79 & 8.13 & 8.09 & 7.84 \\
\hline Below poverty line $(\%)$ & 13.97 & 11.56 & 11.47 & 14.09 & 12.81 & 14.28 \\
\hline Mean household income (\$) & 77,805 & 77,145 & 78,260 & 67,522 & 75,845 & 68,593 \\
\hline
\end{tabular}

Data source GeoLytics (2012c)
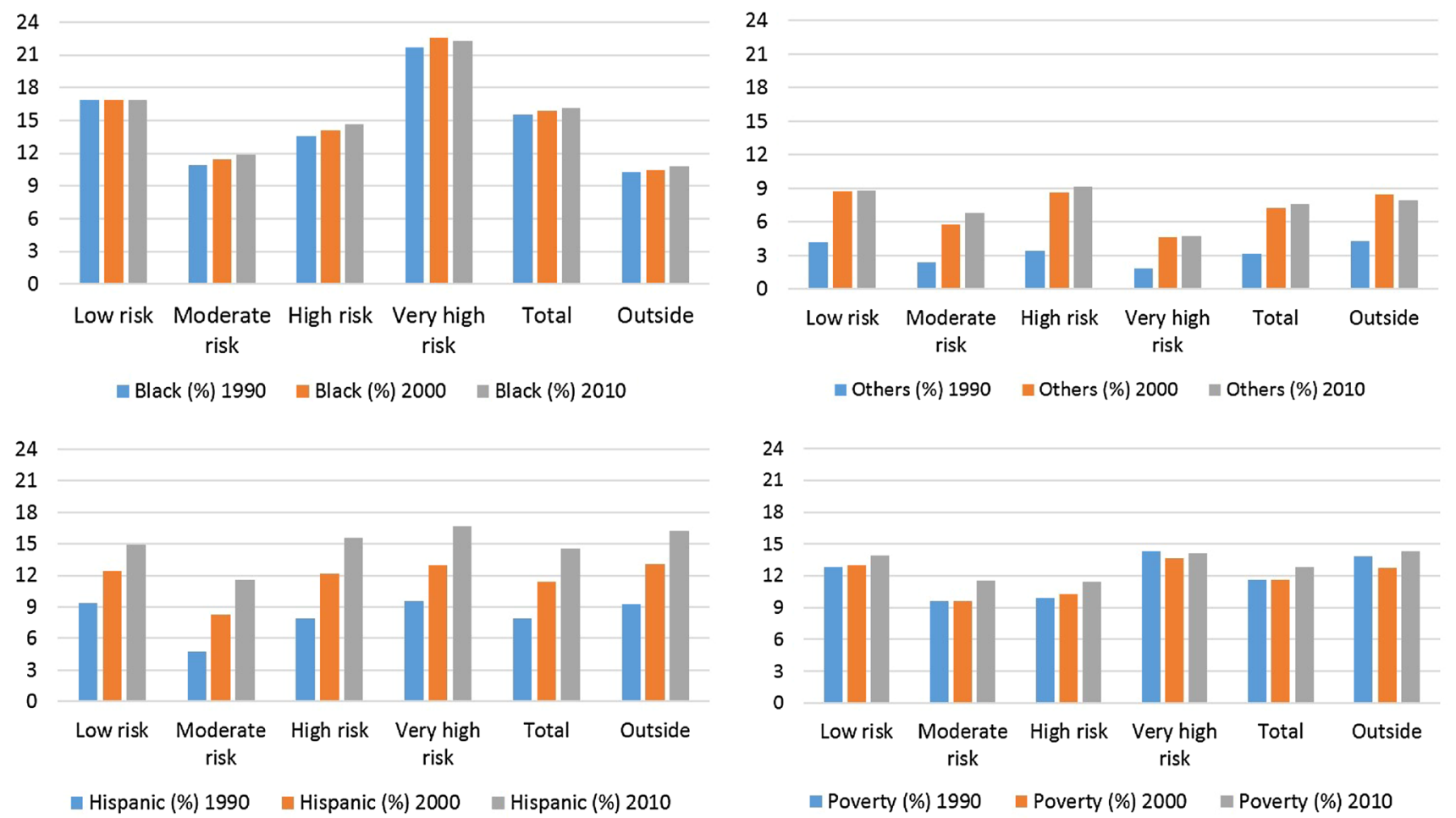

Fig. 5 Demographic characteristics of populations living within a 50-mile radius of a NPP, as sorted by NPP PRI categories in 1990, 2000, and 2010 
Table 4 Changes in demographic characteristics of populations living within a 50-mile radius of a NPP, classified according to four PRI categories using 2010 U.S. Census data

\begin{tabular}{llllllll}
\hline Percent change & Low risk & Moderate RISK & High risk & Very high risk & Total & Outside & Year on year \\
\hline Asian & $59 \%$ & $71 \%$ & $62 \%$ & $45 \%$ & $61 \%$ & $40 \%$ & $1990-2000$ \\
Asian & $35 \%$ & $48 \%$ & $46 \%$ & $44 \%$ & $41 \%$ & $38 \%$ & $2000-2010$ \\
Black & $7 \%$ & $15 \%$ & $21 \%$ & $16 \%$ & $13 \%$ & $16 \%$ & $1990-2000$ \\
Black & $2 \%$ & $10 \%$ & $17 \%$ & $6 \%$ & $7 \%$ & $13 \%$ & $2000-2010$ \\
Color & $33 \%$ & $50 \%$ & $54 \%$ & $33 \%$ & $40 \%$ & $46 \%$ & $1990-2000$ \\
Color & $12 \%$ & $28 \%$ & $30 \%$ & $17 \%$ & $20 \%$ & $25 \%$ & $2000-2010$ \\
Hispanic & $42 \%$ & $92 \%$ & $80 \%$ & $52 \%$ & $59 \%$ & $62 \%$ & $1990-2000$ \\
Hispanic & $22 \%$ & $49 \%$ & $44 \%$ & $37 \%$ & $35 \%$ & $36 \%$ & $2000-2010$ \\
Native American & $28 \%$ & $20 \%$ & $33 \%$ & $31 \%$ & $28 \%$ & $20 \%$ & $1990-2000$ \\
Native American & $-6 \%$ & $-11 \%$ & $-6 \%$ & $-4 \%$ & $-7 \%$ & $3 \%$ & $2000-2010$ \\
Other & $120 \%$ & $161 \%$ & $193 \%$ & $174 \%$ & $150 \%$ & $128 \%$ \\
Other & $3 \%$ & $25 \%$ & $19 \%$ & $9 \%$ & $12 \%$ & $3 \%$ & $2000-2000$ \\
Below poverty line $(\%)$ & 0.13 & 0.01 & 0.35 & -0.67 & -0.03 & -1.10 & $1990-2000$ \\
Below poverty line (\%) & 1.00 & 1.97 & 1.25 & 0.45 & 1.17 & 1.55 & $2000-2010$ \\
\hline
\end{tabular}

\section{Conclusion}

This analysis has provided one potential means of quantifying the level of potential risk associated with a given NPP and has investigated the disparities that exist in the sociodemographic characteristics of the populations that are exposed to different levels of risk. Much of the potential risk associated with NPPs stems from the fact that radiation is produced and may be released by these facilities. Exposure to radiation, regardless of the amount, increases the risk of disease, specifically cancer. A pattern was identified showing that populations living in areas associated with the greatest amount of potential risk tended to include a higher percentage of minorities than did the
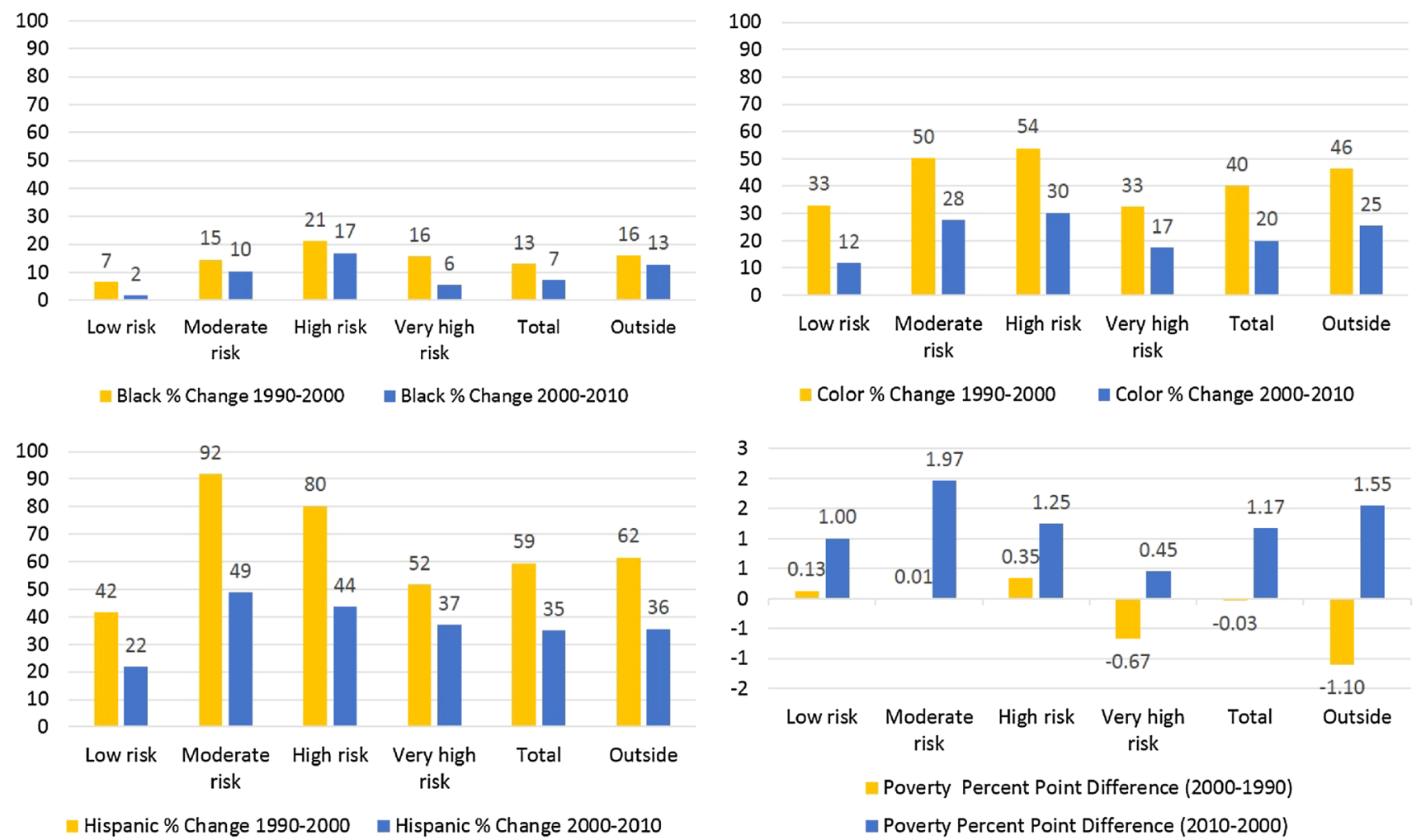

Color \% Change 1990-2000 Color \% Change 2000-2010

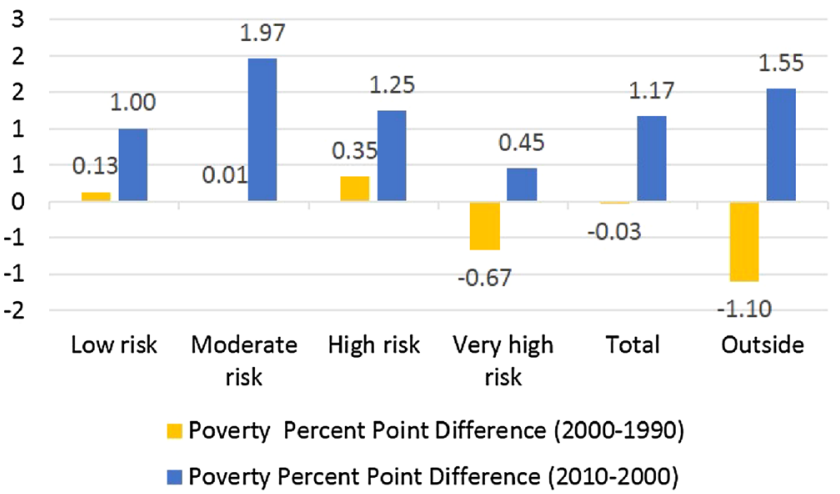

Fig. 6 Changes in demographic characteristics of populations living in host communities of NPPs falling into different PRI levels 
average host community regardless of PRI category as of 1990, 2000, and 2010. This implies that among the at-risk population, different groups of people face different levels of risk associated with or attributable to NPPs. This indicates that there are two layers of environmental justice issues. One layer of environmental justice issues involves those people living in host communities that are within a 50-mile radius of a NPP, who face environmental justice issues deriving from the potential risks associated with the NPP and is made evident when comparing these groups with their counterparts that live outside of those areas (Tables 2, 3). The second layer of environmental justice issues is that, among the populations of the host communities, certain groups-or entire populations at certain NPPs-are exposed to different levels of potential risk, classified here as low risk, moderate risk, high risk, and very high risk, depending on the unique circumstances and location of the individual NPP.

In addition, when the sociodemographic trends over that same time frame were considered, the investigators found that the largest percent changes had occurred in the percent Hispanic and percent Black in the high-risk category. As a percent, the host community population living in moderate risk areas increased during the study period 1990-2010. This implies that the environmental justice issues are on-going and have been in existence for at least three decades. The long-term presence of environmental justice issues facing the NPP host communities, coupled with the large size of such communitiesestimated to be more than one third of the total U.S. population.

The study provided findings that there are environmental justice issues as a result of environmental decision making of siting NPPs without considering unequal impacts of hazards from them. The environmental justice issues have negative impacts on health and wellbeing of people living near the power plants (Kyne 2015). In fact, the environmental justice issues present enormous challenges to all stakeholders seeking to address these issues. In case of extreme events, the emergency evacuation will be very complex and will pose challenges to people who live near the NPPs. We think that participatory decision making among major stakeholders could not be avoided to collectively solve the environmental justice issues.

Open Access This article is distributed under the terms of the Creative Commons Attribution 4.0 International License (http://crea tivecommons.org/licenses/by/4.0/), which permits unrestricted use, distribution, and reproduction in any medium, provided you give appropriate credit to the original author(s) and the source, provide a link to the Creative Commons license, and indicate if changes were made.

\section{References}

Bullard, R.D. 1996. Environmental justice: It's more than waste facility siting. Social Science Quarterly 77(3): 493-499.

Denton, H.R. 1987. The causes and consequences of the Chernobyl nuclear accident and implications for the regulation of U.S. nuclear power plants. Annals of Nuclear Energy 14(6): 295-315.

Eisenhower, D. D. 1953. Atoms for peace. http://voicesofdemocracy. umd.edu/eisenhower-atoms-for-peace-speech-text/. Accessed 12 Aug 2012.

FEMA (Federal Emergency Management Agency). 2013. Earthquake hazard maps. http://www.fema.gov/earthquake/earthquakehazard-maps. Accessed 14 Aug 2014.

Garrick, J. 2003. The current status, safety, and transportation of spent nuclear fuel. The Bridge 33(3): 11-18.

GeoLytics. 2012a. 2000 Census long form in 2010 boundaries. http:// www.geolytics.com/USCensus, 2000-Long-Form-in-2010-Boun daries,Products.asp. Accessed 14 Aug 2012.

GeoLytics. 2012b. Census 1990 in 2010 boundaries. http://www. geolytics.com/USCensus,Census-1990-in-2010-Boundaries,Pro ducts.asp. Accessed 14 Aug 2012.

GeoLytics. 2012c. Census 2010 / American community survey (ACS). http://www.geolytics.com/USCensus,Census2010ACS, Categories.asp. Accessed 14 Aug 2012.

Harris, J.T. 2013. US nuclear power plant radioactive effluents 1994-2009. Center for Advanced Energy Studies. Received the data via email, 20 June 2013.

Harris, J.T., and D.W. Miller. 2008. Radiological effluents released by US commercial nuclear power plants from 1995-2005. Health Physics 95(6): 734-743.

Holt, M., and A. Andrews. 2007. Nuclear power plants: Vulnerability to terrorist Attack. CSR report for Congress. https://fas.org/irp/ crs/RS21131.pdf. Accessed 15 Jun 2012.

ICRP (International Commission on Radiological Protection). 2007. The 2007 recommendations of the International Commission on Radiological Protection. Publication 103. Ann. ICRP 37. http:// www.icrp.org/docs/ICRP_Publication_103-Annals_of_the_ICRP_ 37\%282-4\%29-Free_extract.pdf. Accessed 21 Mar 2015.

Koch, W. 2011. Earthquake readiness of U.S. nuclear power plants is unclear. USA Today. 25 August 2011. http://usatoday30.usatoday. $\mathrm{com} /$ tech/science/environment/story/2011-08-25/Earthquake-readi ness-of-US-nuclear-power-plants-is-unclear/50141704/1. Accessed 10 Sept 2012.

Kyne, D. 2015. Public exposure to U.S. commercial nuclear power plants induced disasters. International Journal of Disaster Risk Science 6(3): 238-249.

Lochbaum, D. 2011. The NRC and nuclear power plant safety in 2010: A brighter spotlight needed. Union of Concerned Scientists: Citizens and Scientists for Environmental Solutions. http:// www.ucsusa.org/sites/default/files/legacy/assets/documents/ nuclear_power/nrc-2010-full-report.pdf. Accessed 15 Aug 2015.

Lochbaum, D. 2012. The NRC and nuclear power plant safety in 2011: Living on borrowed time. Union of Concerned Scientists: Citizens and Scientists for Environmental Solutions. http://www.ucsusa. org/assets/documents/nuclear_power/NRC-nuclear-safety-2011report.pdf. Accessed 15 Aug 2015.

Lochbaum, D. 2013. The NRC and nuclear power plant safety in 2012: Tolerating the intolerable. Union of Concerned Scientists: Citizens and Scientists for Environmental Solutions. http://www. ucsusa.org/sites/default/files/legacy/assets/documents/nuclear_ power/NRC-nuclear-safety-2012-report.pdf. Accessed 15 Aug 2015.

Lochbaum, D. 2014. The NRC and nuclear power plant safety in 2013: More Jekyll, less Hyde. Union of Concerned Scientists: Citizens and Scientists for Environmental Solutions. http://www. 
ucsusa.org/sites/default/files/legacy/assets/documents/nuclear_ power/NRC-Nuclear-Safety-Report-2013.pdf. Accessed 15 Aug 2015.

Lochbaum, D. 2015. The NRC and nuclear power plant safety in 2014: Tarnished gold standard. Union of Concerned Scientists: Citizens and Scientists for Environmental Solutions. http://www. ucsusa.org/sites/default/files/attach/2015/03/nrc-2014-full-report. pdf. Accessed 15 Aug 2015.

Morris-Suzuki, T., D. Boilley, D. McNeill, and A. Gundersen. 2012. Lessons from Fukushima. Greenpeace International. http://www. greenpeace.org/international/Global/international/publications/ nuclear/2012/Fukushima/Lessons-from-Fukushima.pdf. Accessed 14 Aug 2012.

Nebraska Energy Quarterly. 1997. State's first nuclear plant buried near Lincoln. http://www.neo.ne.gov/winter97/win97_12.htm. Accessed 10 Oct 2012.

Nicoletti, G., S. Scarpetta, and O. Boylaud. 2000. Summary indicators of product market regulation with an extension to employment protection legislation. Economics department working papers No. 226, ECO/WKP(99)18. Organisation for Economic Cooperation and Development (OECD). http://www.oecd.org/eco/ outlook/1880867.pdf. Accessed 19 Aug 2012.

OECD (Organisation for Economic Co-operation and Development). 2008. Handbook on constructing composite indicators: Methodology and user guide. http://www.oecd.org/std/42495745.pdf. Accessed 30 Aug 2012.

Perrow, C. 1999. Normal accidents: Living with high-risk technologies: With a new afterword and a postscript on the Y2K problem. New Jersey: Princeton University Press.

Richards, S., T. Frye, J. Shepherd, T. Nicholson, G. Kuzo, U. Shoop, S. Sakai, R. Allen, et al. 2011. Liquid radioactive release lessons learned task force final report. United States Nuclear Regulatory Commission (U.S. NRC). http://pbadupws.nrc.gov/docs/ ML0626/ML062650312.pdf. Accessed 10 Aug 2012.

Tate, E., S.L. Cutter, and M. Berry. 2010. Integrated multihazard mapping. Environment and Planning B: Planning and Design 37(4): 646-663.

The Daily Beast. 2011. Complete methodology: Most vulnerable power plants. http://www.thedailybeast.com/articles/2011/03/16/most-vul nerable-power-plants-complete-methodology.html. Accessed 22 Aug 2012.

Three Mile Island Alert. 2013. Incident chronology at TMI from NRC: 1979-2012. http://www.tmia.com/node/1586. Accessed 17 Dec 2013.

United States Census Bureau. 2010. TIGER/Line ${ }^{\circledR}$ Shapefiles prejoined with demographic data: 2010 census summary file 1 demographic profile (DP1). ftp://ftp2.census.gov/geo/tiger/ TIGER2010/TTRACT/2010/. Accessed 23 Aug 2012.

UNSCEAR (The United Nations Scientific Committee on the Effects of Atomic Radiation). 2012. The Chernobyl accident: UNSCEAR's assessments of the radiation effects. http://www. unscear.org/unscear/en/chernobyl.html. Accessed 15 Aug 2013.

U.S. GAO (U.S. Government Accountability Office). 2012. Spent nuclear fuel: Accumulating quantities at commerical reactors present storage and other challenges (GAO-12-797). http:// www.gao.gov/assets/600/593745.pdf. Accessed 14 Aug 2012.

USGS (United States Geological Survey). 2013. 2008 United States national seismic hazard maps. http://pubs.usgs.gov/fs/2008/ 3018/pdf/FS08-3018_508.pdf. Accessed 23 Jun 2014.

USGS (United States Geological Survey). 2014. U.S. volcanoes and current activity alerts. http://volcanoes.usgs.gov/. Accessed 14 Mar 2014.

U.S. NAS (United States National Academy of Sciences). 2006. Safety and security of commercial spent nuclear fuel storage:
Public report. Washington, DC: Committee on the Safety and Security of Commercial Spent Nuclear Fuel Storage, National Research Council of the National Academies. http://www.nap. edu/catalog/11263/safety-and-security-of-commercial-spent-nu clear-fuel-storage-public. Accessed 20 Oct 2013.

U.S. NAS (United States National Academy of Sciences)/NRC (United States Nuclear Regulatory Commission). 2006. Health risks from exposure to low levels of ionizing radiation: BEIR VII Phase 2. Washington, DC: Board on Radiation Effects Research, National Research Council of the National Academies. http:// www.nap.edu/catalog/11340/health-risks-from-exposure-to-lowlevels-of-ionizing-radiation. Accessed 15 Aug 2015.

U.S. NRC (United States Nuclear Regulatory Commission). 2011. Nuclear Regulartory Commission. http://www.nrc.gov. Accessed 14 Aug 2012.

U.S. NRC (United States Nuclear Regulatory Commission). 2012a. 1Q/ 2012 ROP performance indicators summary. http://www.nrc.gov/ NRR/OVERSIGHT/ASSESS/2012q1/pi_summary.pdf. Accessed 14 Aug 2012.

U.S. NRC (United States Nuclear Regulatory Commission). 2012b. Information digest, 2011-2012 (NUREG-1350, Volume 23). http:// pbadupws.nrc.gov/docs/ML1124/ML11241A096.pdf. Accessed 19 Aug 2012.

U.S. NRC (United States Nuclear Regulatory Commission). 2013a. Backgrounder on chernobyl nuclear power plant accident. http:// www.nrc.gov/reading-rm/doc-collections/fact-sheets/chernobylbg.html. Accessed 19 Aug 2013.

U.S. NRC (United States Nuclear Regulatory Commission). 2013b. Transportation of spent fuel and radioactive materials. http:// www.nrc.gov/reading-rm/doc-collections/fact-sheets/transportspenfuel-radiomats.pdf. Accessed 19 Nov 2013.

U.S. NRC (United States Nuclear Regulatory Commission). 2013c. Backgrounder on decommissioning nuclear power plants. http:// www.nrc.gov/reading-rm/doc-collections/fact-sheets/decommis sioning.html. Accessed 17 Aug 2013.

U.S. NRC (United States Nuclear Regulatory Commission). 2013d. Fact sheet on summary of Japan events in March 2011 and NRC response. http://www.nrc.gov/reading-rm/doc-collections/factsheets/fs-japan-events.html. Accessed 15 Aug 2013.

U.S. NRC (United States Nuclear Regulatory Commission). 2013e. Spent fuel transportation: Risk assessment (NUREG-2125). Office of Nuclear Material Safety and Safeguards, United States Nuclear Regulatory Commission. http://pbadupws.nrc.gov/docs/ ML1212/ML12125A218.pdf. Accessed 24 Aug 2013.

U.S. NRC (United States Nuclear Regulatory Commission). 2014. Status of the decommissioning program. http://pbadupws.nrc. gov/docs/ML1429/ML14294A239.pdf. Accessed 24 Mar 2014

U.S. NRC (United States Nuclear Regulatory Commission). 2015. Information digest, 2015-2016. http://www.nrc.gov/reading-rm/ doc-collections/nuregs/staff/sr1350/v26/sr1350v26.pdf. Accessed 23 May 2015.

Wald, M. L. 2009. Future dim for nuclear waste repository. The New York Times. 5 March 2009. http://www.nytimes.com/2009/03/06/science/ earth/06yucca.html?ref=yuccamountain\&pagewanted=print. Accessed 10 Aug 2012.

World Nuclear Association. 2013. Safety of nuclear power reactors. http://www.world-nuclear.org/info/Safety-and-Security/Safety-ofPlants/Safety-of-Nuclear-Power-Reactors/. Accessed 17 Aug 2013.

Zeller, T. 2011. Experts had long criticized potential weakness in design of stricken reactor. New York Times. 15 March 2011. http://www.nytimes.com/2011/03/16/world/asia/16contain.html? r=0\&pagewanted=print. Accessed 14 Aug 2012. 